\title{
On Application of Automatic Control in Sewage Treatment
}

\author{
Mingli Liu \\ Henan Polytechnic Institute, Nanyang, 473009, China
}

Keywords: Sewage treatment. Automatic control. System

\begin{abstract}
In consideration of the continuous development of electronic technology and computer network technology, the automatic control technology has also been developed increasingly, with application capacity and scope wider and wider. With the high attention to the environmental problems globally, the energy saving and emission reduction and low-carbon economy have been highly concerned unprecedentedly. In this context, the problem of water pollution naturally becomes the focus concerned in the whole society. Therefore, it is quite important to combine the two and apply the automatic control technology in the sewage treatment. In this paper, the necessity of sewage treatment is controlled, and the automatic control system design in sewage treatment is discussed.
\end{abstract}

\section{Introduction}

Today, the development scale of city is larger and larger, the amount of sewage needing treatment is increasing continuously, and the water quality has also become increasingly complex, the limited natural purification function of the water body has been unable to adapt to the requirements for urban sewage treatment and the water environmental protection. The water pollution cause great economic loss, while the lack of water resources also influences the development of society and economy. On the basis of improving the operation efficiency and controlling the operation cost, control system is used to realize the automatic control. Therefore, under the overall trend of enterprise transformation and scale development, it is quite important to introduce automatic control system to improve the overall operation efficiency.

\section{Necessity of sewage treatment}

The per capita availability of water resources in China is relatively small, and the spatial distribution is imbalanced. With the continuous acceleration of urbanization and industrialization process of China, serious drought has appeared in many places to the extent that the demand defection of water resources is continuously increasing. Based on this background, the sewage treatment has become an emerging industry with great development prospect, with the same important position as the running water production, water supply, water drainage and the use of reclaimed water. At present, the sewage treatment industry in China is continuously developed, the sewage treatment amount is increasingly quite rapidly, especially the rapid increasing of urban sewage treatment amount, causing that the control of operation cost and improving the treatment efficiency of sewage have become the major realistic problem faced by the sewage treatment industry of China. Applying the automatic control technology can trace the frequently changing water treatment condition, detect the water quality data in different periods, and it is possible to present them in computer dynamically, making it convenient to comprehensively analyze and treat the above data for reference in need. Meanwhile, it is also possible to adjust relevant parameters of the equipment by analyzing the trend and routine, so as to realize the objective of optimal control state and energy saving. Using computer technology to replace manual operation can reduce the accident rate as far as possible, guarantee the safety better, reduce the labor strength, save manpower and materials and improve the reliability of equipment operation. 


\section{Automatic control system design in sewage treatment}

The control design of the present system is mainly in the form of local control/remote control and realized mainly by improving real-time switching of the secondary circuits, contactor and intermediate relay in the pump control box. In normal condition, it is possible to select to place the switch on the remote control position, once in case of problem of remote control system, it is needed to switch into the local control method on site. The remote control includes two major control forms, intermediate soft manual (inching) and automatic control, while the switching mode is to click relevant buttons in the middle of the intermediate control monitoring image.

\section{Grid unit design}

The grid unit is mainly used to eliminate the coarse suspended and foreign matters in the water, so as to protect that various follow-up treatment facilities can effectively operate. In general, it is required to respectively design the grid and fine grid according to the water source condition. The former mainly eliminates the coarse suspended matters that might block the water pump unit and the pipe valve, while the latter mainly eliminates the fine fibers presented suspended state that cannot be eliminated by the coarse grid. The water is supplied by the pump station, when the water comes from the pump station, the screening conducted by the coarse grid has been implemented

\section{Water inlet pump room unit design}

The water inlet pump room belongs to the great power consumer of the whole sewage treatment plant, implementing reasonable control can have a good energy saving effect. To this end, it is required to achieve the following requirements: first, avoid the frequent starting and stop of pump as far as possible; second, make the pump in the high-level operation state as far as possible and third, ensure that all pumps can be of balanced use. The traditional control is mainly to start the pump manually according to the level and experience. Therefore, the most common in on-site automatic control is to operate by segment according to the level, and the number of pumps started in different stages is different and the pumps are applied alternatively. Generally, the setting of level difference in the low and middle-level stage is relatively wide, while the level difference in the high-level stage is set relatively narrowly usually, the purpose of which is not to avoid frequent starting and stop during the low-level stage, but to ensure that the operation efficiency is improved during the high-level operation of pumps as far as possible. Although there also exists the condition of constant level frequency conversion control, most of the equipment currently used is of one for use and one for standby, that is to say, only the small sewage treatment enterprises will use one frequent converter to drive two pumps.

\section{Improved SBR chamber unit design}

There is a lot of equipment involved in the improving of SBR chamber, and the control requirements of time section are also very high with abnormally complex requirements, and this require to adopt the full-automatic control mode, minimize the artificial manual operation or the artificial central control point. There are four groups of SBR chambers, and the SBR chamber system is according to a certain cyclic process. Each cycle can be divided into the following different stages, respectively inflow, sedimentation and water drainage. Each group of cyclic operation is automatically controlled by PLC, and the arrangement in various different stages is prepared in advance, but if needed, it is possible to make a reasonable adjustment in the PLC system. The method of program control is as follows:

First, the on-site water inflow is neither stable nor regular. When the water inflow is large, if operating in full cycle, the SBR chamber might overflow, while the water inlet valve is also controlled by the level. Once the high level is reached, the water inlet valve should be changed not necessarily after the cycle is ended.

Second, as the process of nitration and anti-nitration is simultaneous in the SBR chamber, it is extremely important to adjust the aeration amount. It is required to arrange the aeration time more flexibly when the water flows in, while the aeration amount should be controlled below $0.5 \mathrm{mg} / \mathrm{l}$ and it is required to control by adjusting the aperture of the motor valve. Specifically, it is needed to determine after the on-site debugging. The valve of aeration should be opened completely during the 
aeration stage, while the aeration amount should reach $2 \mathrm{mg} / \mathrm{l}$, and it is required to control it with the frequency of blower. When the water flows in, it is needed to control the aperture according to the aeration requirements, and another important reason is that just at the end of the water drainage of water inflow chamber, the level is relatively low, therefore the aeration chamber will not be aerated enough on the contrary.

Third, blower is the most important equipment, which is permanently open generally in the system operation, and in this process, no air duct blockage is allowed. Therefore, it is required to always maintain an air inlet in the state of full opening, while the on-site air inlet valve is of a butterfly valve structure, with extremely short starting and stopping time. Once if it is required to close an air inlet valve, it is required to close it only after the opened one is opened in place.

Fourth, after the sedimentation time is reached, the water decanter gradually falls, when falling to the effective level, it will rise automatically to wait for the work of the next cycle after rising in place.

Fifth, the mud valve can be of two different control modes, one is to jointly act with the water inlet valve, that is when the door of the water inlet valve is opened, the water inlet chamber drains the mud simultaneously, and the second is to joint act with the water decanter, when the water decanter falls somewhat, the mud valve is opened simultaneously, i.e. the water decanter drains the mud simultaneously.

Sixth, it is required to determine whether to open the remaining sludge pumps according to the concentration point control of the sludge. At the time of starting, the mud valve drains the mud during water decanting. When the level in the selection tank reaches the high-floating ball level, it is required to stop the water inlet pump forcefully. And the floating ball setting here controls the quantity of start and stop of the water inlet pump, and it is only needed to select the level which has not reached the high floating ball, even if all water inlet valves are closed, it is only needed to down-regulate the frequency of the frequency conversion pump without closing.

Seventh, once in case of fault in a tank, the remaining SBR tanks still operate according to the cycle set, and the tank with fault must be changed to be of manual control or central control inching. Only when some valves are in fault state the remaining valves can still implement automatic action according to the fixed cycle, and the operators only need to operate the valves with fault, in this way, it is possible to reduce the artificial participation and the probability of error in artificial participation. It can be seen that the valve has a flexible requirement for the control, therefore there are many factors involved. Through careful thinking, the author thinks that applying the method of implicit control can realize the partial thought of overall design.

\section{Blower room unit design}

The blowing system is a badly lagged control system, which is very difficult to be realized usually if the general PID control algorithm is used. Therefore, it should be designed in combination with the actual condition. For example, $2 \mathrm{mg} / \mathrm{L}$ dissolved oxygen is the minimum limit, and should not be required to be controlled to the target value, and the DO detection instrument also will generate some errors, causing that the detection result is only for reference, and the minimum frequency of the blower should not be too low, otherwise it is quite easy to cause the thermal relay fault and large noise, and the minimum frequency of the blower on site should not be below $25 \mathrm{~Hz}$. Once the power frequency blower is started, its minimum frequency will be up to above $45 \mathrm{~Hz}$, if the DO value at this time is still lower than $2 \mathrm{~m} / \mathrm{L}$, there will be an alarm, and artificial inspection is conducted for pipe problem. The blower equipment is extremely important, therefore, it is extremely important to take the corresponding protective measures. Once all air inlet valves are in the state of being closed in place, it is required to stop all blowers, and if there is no air inlet valve in the state of being opened in place, but there is signal in half-open state, the blower equipment should also be stopped as long as this condition lasts for above $5 \mathrm{~s}$.

\section{Chorine dosing room unit design}

The main equipment of the chorine dosing room is composed of two sets of axis-flow booster pumps (one for use and one for standby) and two sets of chlorine dioxide generators in sequential control. First start the axis-flow booster pump, after about 30s, start the chlorine dioxide generators, it is mainly because the disinfection process is mainly in the principle of negative pressure, only when 
the negative pressure reaches a certain degree can the chlorine dioxide generators mix the disinfection solution with water for disinfection. During the stop, the control system can be stopped automatically in emergency only in case of fault of two booster pumps or two chlorine dioxide generators.

\section{Dehydration machine room unit design}

The dehydration machine room mainly consist of three thickening and dehydration machines, one spiral conveyor, two dosing pumps, two cleaning pumps, two sludge adding pumps, two dephosphorization dosing pumps and several mixers, in which the sludge adding pump is mainly responsible for conveying the sewage in the concentrated sludge storage tank to the dehydration machine; the cleaning pump is mainly used to clean the dehydration machine filter and is disinfected, while the water is from the contact tank where the chorine dosing unit is used; the dosing pump is mainly responsible for conveying the agent in the PAM tank to the dehydration machine; the dephosphorization dosing pump is used for the improved SBR tank for chemical dephosphorization if necessary. In the mixers, one is used for the polyaluminium tank (dephosphorization), one used for mix the sludge in the sludge storage room and the remaining are used in the PAM tank. The control method is as follows: the system is started according to a certain sequence overall, and the main starting sequence is to start the cleaning pump and conveyor, and then start the dehydration machine and PAM tank mixer and finally the sludge adding pump and dosing pump, while the stop sequence is the opposite. The mixer in the sludge storage room is inched manually above one hour before starting the dehydration system, while the mixer in the polyaluminium tank and the dephosphorization dosing pump does not belong to the dehydration system but are inched manually. After starting the system, it is only needed to adjust the level in the concentrated sludge storage room. The automatic-control program of the dehydration machine is mainly selected and started manually, and it is only needed to switch it to the automatic control state. The system will operate immediately after being started, while the manually selected equipment will remind whether the pipeline is correct in the configuration interface. As the dehydration system does not operate for a long time, but drains sludge reasonably if needed, a better economic effect will be obtained by using this control solution, and the PAM tank miser will not influence the automatic operation $\mathrm{f}$ the whole system, but it is only needed to start simultaneously with the dehydration machine when it is under the automatic control state, of course, manual operation is also available when the system is switched to inching state or local remote control state.

\section{Conclusion}

As stated above, water is one of the important factors for the sustainable social and economic development of China, while sewage is one of the causes to influence the sustainable development of many cities. In recent years, with the continuous development of automatic control technology, the control system has also been improved accordingly. Introducing automatic control technology in sewage treatment can greatly improve the sewage treatment efficiency, while the sustainable development of sewage treatment will also improve the performance of relevant control systems, with a very great market value and far-reaching significances.

\section{References}

[1] Cai Chuancheng, Full Process Strategy and Method for Automatic Control of Sewage Treatment Plant, Science and Technology Information, 2012 (4)

[2] Wang Jiaquan, Application of Automatic Control in Sewage Treatment [J] Industrial Water \&Wastewater, 2012 (6)

[3] Liu Yang, Brief Discussion on Brief Automatic Control in Sewage Treatment [J] Heilongjiang Science and Technology Information, 2012 (30).

[3] Wu Haifeng, Research on Application of Automatic Control System in Sewage Treatment [J], Science and Technology Innovation Herald, 2013 (14) 
[5] Wang Yong, Discussion on Reconstruction Proposal for Automatic Control System of Sewage Treatment Plant [J], Henan Science and Technology, 2013 (16) 